\title{
Comparisons of Endothelial Dysfunction, Inflammation and Insulin Resistance in Differentiated Thyroid Cancer Patients According to Their Radioactive Iodine Treatment Status
}

\author{
Mustafa DINÇ ${ }^{1}$, Kamil BAŞKÖY ${ }^{1}$, Ramazan YILDIZ ${ }^{2}$, Serkan TAPAN ${ }^{3}$, Engin ALAGÖZ ${ }^{4}$, Fatih YEŞILDAL $^{3}$, Erkan ÖZTÜRK ${ }^{2}$, \\ Abdullah TAŞLIPINAR ${ }^{1}$, Aydoğan AYDOĞDU ${ }^{1}$, Salih DEVECI ${ }^{5}$, Nuri ARSLAN ${ }^{4}$, Ömer AZAL ${ }^{1}$, Alper SÖNMEZ ${ }^{1}$ \\ 1 Gulhane Military Medical Academy, Department of Endocrinology and Metabolism, Ankara-TURKEY \\ 2 Gulhane Military Medical Academy, Department of General Surgery, Ankara-TURKEY \\ 3 Gulhane Military Medical Academy, Department of Biochemistry, Ankara-TURKEY \\ 4 Gulhane Military Medical Academy, Department of Nuclear Medicine, Ankara-TURKEY \\ 5 Gulhane Military Medical Academy, Department of Pathology, Ankara-TURKEY
}

\section{Objectives:}

\section{Methods:}

\section{Results:}

Conclusions:

Radioactive iodine (RAI) treatment has been reported to be associated to increased cardiovascular events and death compared to the general population, but the mechanism is not fully understood. Endothelial dysfunction, inflammation, and insulin resistance play important roles in the pathogenesis of atherosclerotic events. We aimed to compare papillary thyroid carcinoma patients receiving levothyroxine suppression therapy after bilateral total thyroidectomy with or without RAI treatment in terms of endothelial dysfunction, inflammation and insulin resistance.

A total of 30 patients were included in the study $(\mathrm{F}=23(76.6 \%)$; age $=38.83 \pm$ $8.15(\min =24, \max =54)) .17$ of these patients $(\mathrm{F} / \mathrm{M}=14 / 3)$ received RAI ablation. In all cases, blood samples were taken before the operation. Blood samples were taken at 3 and 6 months after RAI or thyroid surgery. All patients with $\mathrm{TSH}<0.1 \mu \mathrm{IU} / \mathrm{ml}$ received levothyroxine suppression therapy. Serum asymmetric dimethyl arginine (ADMA), hs-CRP and HOMA-IR measurements were performed to demonstrate endothelial dysfunction, endothelial inflammation and insulin resistance, respectively.

RAI receiving and not-receiving groups were similar in terms of age and gender. TSH levels were significantly lower than before treatment $(p<0.001)$. Preoperative ADMA, HOMA-IR and hs-CRP levels were similar to 3rd and 6th month measurements. These parameters were similar between groups receiving and notreceiving RAI treatment. Changes in ADMA, hs-CRP and HOMA-IR levels were not associated with the amount of applied RAI.

In this study, there was no significant effect of RAI ablation treatment on endothelial dysfunction, inflammation and insulin resistance in differentiated thyroid cancer patients. However, in order to better clarify the effects of RAI applications on these parameters, larger scale long-term follow-up studies are needed. 